\title{
Psychometric properties of the Inventory of Complicated Grief in Mexican community sample during COVID-19
}

\section{pandemic.}

\begin{abstract}
Alejandro Domínguez Rodríguez¹, Esteban Eugenio Esquivel Santoveña², Sarah Margarita Chavez-Valdez ${ }^{3}$, Reyna Jazmín Martínez Arriaga ${ }^{4}$, María Jesús Hernández Jiménez ${ }^{1}$, Eduardo Bautista Valero ${ }^{5}$, Rosa Olimpia Castellanos Vargas², Carlos ArzolaSánchez ${ }^{6}$, Flor Rocio Ramírez-Martínez², Anabel de la Rosa Gómez5, Paulina Erika Herdoiza Arroyo ${ }^{7}$, Paulina Arenas-Landgrave ${ }^{8}$ \& Sofia Cristina Martínez-Luna ${ }^{8}$
\end{abstract}

1 Health Sciences Area, Valencian International University, Valencia, Spain

2, Universidad Autónoma de Ciudad Juárez, Ciudad Juárez, Mexico

3, Escuela Libre de Psicología, A.C. Universidad de Ciencias del Comportamiento, Chihuahua, México.

4 University of Guadalajara, Mexico

5 Facultad de Educación Superior Iztacala, Universidad Nacional Autónoma de Mexico, Mexico

6 Universidad Tecmilenio, Juarez, Mexico

7 International University of Ecuador, Ecuador

8 National Autonomous University of Mexico, Mexico

\section{Abstract}

Objective: The aim of the present study was to validate the Inventory of Complicated Grief (ICG) in the adult population, since there is no valid instrument that evaluates this construct in the Mexican population. 
Method: This study was based on an Ex Post Facto, instrumental design with a convenience sample. The ICG was applied to 4014 participants (3540, females, 470 males and 4 individuals classified as other) who had experienced a loss of a loved one during the COVID-19 pandemic. Exploratory and confirmatory factor analyses were conducted. The internal reliability of each factor was examined by means of the Cronbach's alpha index ( $\alpha$ ). Correlation analyses between the ICG, the Center for Epidemiologic Studies Depression Scale, the Satisfaction with life scale and the Beck's Hopelessness Scale were performed to assess convergent and divergent validity of the ICG.

Results: The ICG showed a high internal reliability with a Cronbach alpha of 0.92 . The confirmatory factor analysis demonstrated that a four-factor model of the ICG (normal grief symptoms, emotional-anxious detachment, intense negative emotions, loss-impairing anxiety) fits the data well. According to bivariate analyses the ICG was correlated with measures of life satisfaction $(r=-.208, n=1984, p=.001)$, hopelessness $(r=.522, n=$ 1984, $p=.001)$, and depressive symptoms $(r=.641, n=1984, p=.001)$.

Conclusions: The ICG with a Mexican sample is valid, with good psychometric properties and an appropriate measure of complicated grief for Mexican adults.

Keywords: Loss, Grief, Inventory of Complicated Grief, COVID-19, Psychometric Validation, Mexican Sample.

\section{Clinical impact statement}


This study suggests the use of the Complicated Grief Inventory validated in the Mexican adult population during the COVID-19 pandemic, a developing country, where instruments and psychological services are scarce. This validation showed adequate psychometric properties. This inventory can be useful to identify those who require psychological attention due to complicated grief disorder, and thus, through psychological interventions to avoid further complications for the mental and physical health.

\section{Introduction}

The COVID-19 epidemic has spread globally disrupting the existence of millions. According to data from the World Health Organization (WHO), 2,787,593 million deaths have been registered worldwide, being the region of the Americas with the highest death toll, around 1,340, 530, up until March 30, 2021 (WHO, 2021). Mexico is one of the countries with most deaths reported due to COVID-19, representing the third place 
worldwide, with 202,209 deaths, until March 30 (Johns Hopkins University, 2021). The circumstances surrounding death from / within the COVID-19 pandemic have caused a different traumatic experience from other types of deaths / losses (Kokou-Kpolou et al., 2020).

The grieving process is defined as the natural response to the loss of any person, thing, or value with which an affective bond has been built, and as such, it is a natural and human process, not a disease that must be avoided, or from which a person heals (Grochot, 2018). The role of the grieving process is to elaborate the loss impact and adapt to the new situation that is being experienced (Payas, 2010).

Despite the fact that most people that are in a process of grief recover in a relatively short period of time, there are circumstances that complicate this process, increasing the intensity and time of mourning, presenting a complicated grief (CG) (Morris, Moment \& deLima, 2020). According to Prigerson et al. (1995), CG can be identified from the following symptoms: "preoccupation with thoughts of the deceased, searching and yearning for the deceased, disbelief about the death, crying, being stunned by the death, and not accepting the death" (p.66).

Derived from the Coronavirus disease (COVID-19) pandemic, there has been an increase in the prevalence of CG, causing severe and dysfunctional symptoms over an extended period of time, in response to loss of a loved one. Bereaved people due to COVID-19 losses showed higher symptoms of prolonged grief disorder compared to people with natural and unnatural loss (Eisma et al., 2021). The social distancing requirements, the funeral or ceremonies restrictions, and the inability to seek support, are 
some of the factors that could increase CG in the current pandemic (Bertuccio \& Runion, 2020).

In the current context of the COVID-19 pandemic, the evaluation of the manifestations of complicated grief must be evaluated and carefully considered according to the country's context (Kokou-Kpolou et al., 2020). Currently there are measures to assess grief, however, it is necessary to have instruments that allow us to differentiate a normal grief from those that are pathological or complicated, in order to intervene and facilitate adjustment to the loss of the bereaved (Prigerson et al., 2009).

The Inventory of Complicated Grief (ICG) created by Prigerson (1995) and adapted to Spanish by Limonero (2009) has been one of the most widely used scales to evaluate CG, showing adequate levels of reliability and viability (Lifshitz et al., 2020; Han et al., 2016). In addition, it has been found that the ICG is a more sensitive instrument to detect cases of CG and it is better suited to discriminate among severities of CG, compared to other scales (Igarashi et al., 2020).

The ICG has been validated in different countries such as Israel (Lifshitz et al., 2020), Korea (Han et al., 2016), Poland (Ludwikowska-Świeboda, \& Lachowska, 2019), Italy (Carmassi et al., 2014), Colombia (Gamba-Collazos \& Navia, 2017) and Spain (Limonero et al., 2009).

In the study by Lifshitz et al. (2020), the correlations between the scores of the three factors were significantly positive, indicating important convergent validity. Furthermore, Cronbach's alpha for the 17-item measurement was 0.91 . These results strongly support a three-factor structure: emotional distress, longing for the deceased, and socio-emotional detachment. The associations between the three factors showed that 
each factor explained a unique variation in CG. Han et al. (2016) validated the ICG among 1,138 Korean adolescents. The internal consistency of the 19-item Korean version of the ICG was good (Cronbach's $\alpha=0.87)$. Ludwikowska-Świeboda, \& Lachowska (2019), verified the psychometric properties of the Polish version of the ICG with 278 participants who experienced the loss of a close relative or friend. The statistical analysis carried out showed that the measure was a reliable and valid tool $(\alpha=0.94)$. Carmassi et al. (2014), included 171 grieving participants of whom 64 were clinically diagnosed with CG and 58 healthy controls that were evaluated with the Italian version of the ICG. The total ICG mean score was significantly different between the study groups $[F(3,228)=94.19, p$ $<0.001]$. Games-Howell post-hoc comparisons indicated significantly higher scores in CG patients and significantly lower scores in healthy controls. The scale demonstrated a high level of internal consistency ( $\alpha=0.95)$. In Latin America, Gamba-Collazos \& Navia (2017), carried out the adaptation of the ICG in Colombian population, with a sample of 120 voluntary participants. The authors established that scores greater than 25 corresponded to CG and found that the scale had high levels of internal consistency $(\alpha=0.94)$ and testretest reliability $(r=0.80)$. The Spanish adaptation (Limonero, et al., 2009) had a Cronbach's Alpha $=0.88$ and a correlation of $r=0.81$ in the test-retest comparison. According to the authors, this inventory has high levels of internal consistency ( $\alpha=0.92$ in clinical population and $\alpha=0.93$ in university population) and temporal stability in testretest applications $(r=0.93)$. In any case, studies with a larger sample are required to allow the evaluation of the instrument's properties against different population groups.

Indeed, more research is necessary to better understand the structure of symptoms of the complicated of grief process. According to the validation of the ICG carried out by 
Limonero et al. (2009), three factors related to CG were observed, unlike the original scale (Prigerson et al., 1995) and the Italian validation (Carmassi et al., 2014) where only a single factor was related to CG. This allows us to understand the multidimensionality of the CG construct (Gamba-Collazos \& Navia, 2017; Masferrer et al., 2017). Therefore, it is necessary to continue studying the psychometric properties of the ICG, according to the context in which it is applied, as Masferrer et al. (2017) indicates, clinical instruments tend to behave differently depending on the type of population to which they are applied. Based on the validations that have been conducted on the ICG, the study of both reliability and validity can be identified, through internal consistency and test-retest comparisons, as well as with analyses that allow to ascertain the validity of the convergent and divergent construct through correlations with other scales (Gamba-Collazos \& Navia, 2017; Lifshitz et al., 2020; Limonero et al., 2009; Masferrer et al., 2017).

In addition, the construct validity or factorial structure of the ICG has been analyzed. This method is widely used in the discipline of psychology for the validation of measurement scales when structural models are proposed, since these allow the empirical contrast of models that include causal effects between certain variables (Martinez \& Caro, 2009). According to Thompson (2004) there are two kinds of factor analysis, the first is the Exploratory Factor Analysis (EFA), used when the researcher is not clear about the nature of the relationship between the measured variables; the second corresponds to the Confirmatory Factor Analysis (CFA) where the causal relationships of the variables are tested, which allows the adjustment of the model.

Despite being a widely used scale in different countries, the ICG has not yet been validated with Mexican population. Thus, the objective of this study was to obtain the 
psychometric data of the ICG in a Mexican community sample, since being one of the countries with the highest number of deaths worldwide (Johns Hopkins University, 2021), it would allow estimating the prevalence rates of CG and thus proposing intervention strategies for people who meet the criteria of a CG. Thus, the objective of this study was to obtain the psychometric data of the ICG because there is no valid and reliable version for the Mexican adult population and, likewise, to avoid the methodological error of using translations of instruments developed for other cultures without the proper validation analysis (Sousa \& Rojjanasrirat, 2011).

\section{Method}

\section{Aims}

To adapt and validate the ICG in the Mexican adult population that suffered a loss due to COVID-19 or for any other cause during the COVID-19 pandemic.

\section{Methods and Analysis}

This study was based on an Ex Post Facto, instrumental design with Intentional Sample. The study was directed at Mexican participants who had experienced the loss of a loved one during the COVID-19 pandemic and who were invited to access a free online intervention delivered in Spanish, aimed at individuals to prevent complicated grief (Masked). The dissemination of the online intervention was done through digital social networks, articles and journalistic notes, invitations through specialists and civil associations in Mexico, and snowballing sampling from mid-December 2020 to midFebruary 2021. Prior to the intervention, individuals had to read the online informed consent, and once approved, continue to complete online-delivered measures on several mental health indicators, including a complicated grief measure. Ethical approval was 
obtained from the Autonomous University of Juarez's board of Ethics prior data collection commencement.

For the analysis, the sample was randomly divided into two subsamples in SPSS version 23 to obtain homogenous groups. One of the subsamples was used to conduct EFA, and a second subsample was used to perform a CFA. Firstly, an EFA was carried out to verify the original factor structure of the Inventory of Complicated Grief validated in Spanish population (ICG; Limonero et al., 2009). Secondly, a CFA was conducted to corroborate the factor structure found in our EFA.

\section{Participants}

A total of 4015 participants were obtained, but one requested to be removed from the study, therefore a 4015 female $(88.2 \%)$, male $(11.7 \%)$ and $(.1 \%)$ classified as "Other" Mexican participants were recruited from an online psychological intervention for the prevention of complicated grief (Domínguez-Rodríguez et al., 2021) with an age range from 25 to 60 years old, mean age of $36.3(S D=8.5)$ years. Most participants $(59 \%)$ manifest they are "currently working", while others (41\%) describe themselves as "currently not working".

\section{Psychological measures}

Inventory of Complicated Grief (ICG)

This scale includes 19 items within a five-point Likert-type scale ranging from 0 to 4 , where: 0 = "never", 1 = "rarely, 2 = "sometimes", 3 = "often" and 4 = "always". The items evaluate the frequency of the explored symptoms type (emotional, cognitive, or behavioral). For its evaluation, the points of each item are added, and the total scale 
scores range between 0 and 76 points. A score above 25 is an indicator of CG. The properties of the adaptation of the scale to Spanish have good results of internal consistency $(\alpha=0.88)$. The version of Limonero et al. (2009), was applied for this study.

Center for Epidemiologic Studies Depression Scale (CES-D)

Depression levels were assessed by means of the CESD-D, a self-report scale that assesses symptoms of depression within the past two weeks. This scale consists of 35 questions and contains four possible answers: rarely or never (less than 1 day), sometime or rarely (1-2 days), occasionally or a good part of the time (3-4 days) and most of the time (5-7 days). This measure has been constantly used in health research and its psychometric properties prove to be a valid scale in Mexican population $(\alpha>.90)$, according to González -Forteza et al. (2011).

\section{Satisfaction with Life Scale}

This scale consists of 5 items in which participants indicate how much they agree with each question, with an answer option in a Likert-type format ranging from 1 (totally disagree) to 7 (totally agree). The scores range from a minimum of 5 to a maximum of 35 , where the highest scores indicate greater satisfaction with life (Vázquez et al., 2013). This scale has been validated in Mexican population, obtaining good results of internal consistency ( $\alpha=0.74$; López-Ortega, et al., 2016).

Beck's Hopelessness Scale.

This scale is composed of 20 items with a dichotomous answer option (false or true). The score ranges from 0 to 20 with higher scores indicating a higher level of hopelessness 
(Beck et al., 1974). It is a widely validated and used scale, and for this study the version validated in the Mexican population was applied (Osnaya et al., 2012).

\section{Results}

The sample used in the EFA was composed of 2,030 participants, while the sample used in the CFA was composed of 1,984 individuals. There were no statistically significant differences between the two samples in sociodemographics and in levels on the ICG.

\section{Exploratory factor analysis}

The 19 items of the ICG were analyzed using EFA, using the principal axis factors method recommended when data are not normally distributed, as previously checked through QQ plots - not shown (Costello \& Osborne, 2005). The Kaiser-Meyer-Olkin (KMO) Index was .70 and the Bartlett's sphericity test ( $p>.001)$ indicated appropriateness of the sample to conduct factor analyses (Tabachnick \& Fidell, 2007). If the highest factor loading of an item was lower than .30 , the item was eliminated, and if an item had a shared factor loading (factor loadings difference less than .20), the item was removed.

The final scale had 14 items with unique factor loadings ranging from .31 to .74 (see Table 1). Items $7,12,13,15$, and 17 did not conform to the resulting four factor structure found through EFA. Table 1 shows factors loadings and communalities for the EFA of the ICG scale. The first factor explained $15.1 \%$ of the total variance and it is composed of four items (items $3,4,5$, and 14 ) with factor loadings ranging from .38 to .64. According to the theme of these items this factor was labelled "Normal-grief symptoms". The second factor explained $10 \%$ of the total variance and it is composed of three items (items $9-11$ ) with factor loadings ranging from .53 to .57 . According to the theme of these items this factor 
was labelled "Emotional-anxious detachment". The third factor explained $8.3 \%$ of the total variance and it is composed of four items (items 6,17 -19) with factor loadings ranging from .31 to .62 According to the theme of these items this factor was labelled "Intense negative emotions". The fourth factor explained $7.6 \%$ of the total variance and it is composed of three items (items $1-2$, and 8) with factor loadings ranging from .34 to .74 . According to the theme of these items this factor was labelled "Loss-impairing anxiety".

\section{Confirmatory Factor Analysis}

A sample of 1,984 participants performed the cross-validation and finally, the confirmatory factor structure. This factor structure was verified through structural equation modelling (SEM) using AMOS version 21. Testing whether measures of this construct were consistent with researchers' understanding of complicated grief in a Mexican sample, also known as confirmatory factor analysis (CFA), revealed four factors with the corresponding items in the exploratory factor analysis (see Table 1). The measure of fit between the hypothesized model and the observed covariance matrix, also known as the goodness of fit index $(G F I)=.92$, the SRMR standardized root mean squared residual fit index $(S R M R)=.04$, the discrepancy between the data and the hypothesized model measure for model fit, also known as comparative fit index $(\mathrm{CFI})=.94$, the Tucker- Lewis index a conventional cutoff value under maximum likelihood $(T L I)=.92$, the root mean square error of approximation (RMSEA) $=.08$, as stated by Shi, Lee \& Maydeu-Olivares (2018) an RMSEA $\leq .06$ could be considered. Both RMSEA and SRMR suggest the model has an

acceptable fit. The model of fit indexes concerning the chi-square had the following results: The $X^{2}$ with 70 degrees freedom was equal to $14.75(p<.001)$. Other Indexes 
values were: $\mathrm{NFI}=.94, \mathrm{AGFI}=.90$. The obtained indexes report an adequate model fit. Item loadings for this model ranged from .57 to .99 (Figure 1)

\section{Internal reliability}

The internal reliability of each factor was ascertained by means of the Cronbach's alpha index ( $\alpha$ ). The CFA Cronbach's alpha values for each of the four factors ranged from .64 to .77 (see Table 2). Most of the values are adequate in cross-validation for both exploratory and confirmatory groups. The reliability for the complete scale was $\alpha=.92$.

Evidence of convergent (and divergent) validity of the validated ICG was corroborated through bivariate analyses resulting in statistically significant correlations with measures of life satisfaction $(r=-.208, n=1984, p=.001)$, hopelessness $(r=.522, \mathrm{n}=1984, p=.001)$, and depressive symptoms $(r=.641, n=1984, p=.001)$.

\section{Discussion}

The objective of this study was to adapt and validate the Inventory of Complicated Grief with adult Mexican population, one of the most affected countries due to the COVID-19 pandemic that has caused over 200,000 deaths related to this virus. In this sense the scale was validated with the general population searching for psychological treatment due to a recent death of a loved person during the previous six months or more. This scale was already validated in Spanish population by Limonero, et al., (2009), and in Colombia by Gamba-Collazos \& Navia (2017), but not in Mexico.

The ICG was validated with Mexican adults, both for the EFA, and the CFA yielded a fourfactor solution: 1) normal grief symptoms, 2) emotional anxious detachment, 3) intense negative emotions, and 4) loss impairing anxiety. The normal grief symptoms are reflected in the items for the first factor, here labelled as "normal grief symptoms", feelings of 
emptiness, nostalgia, sadness, and melancholia, for example: "I feel like I can't accept the death of my loved one". In regard to the first factor, Boelen \& Smid (2017) indicate that prolonged grief disorder can be posited after six to 12 months of a loss suffering, and to determine a complex or an uncomplicated grief, a key indicator can be the distress and disability caused by these reactions and their pervasiveness. The results of the present study are in line with Boelen et al. (2010), in that they find reactions and difficulties directly associated with the loss such as longing for the loved one, intrusive ideas about the deceased and their death, sadness or anger at the loss and even denial of the loss. The second factor refers to an "emotional anxious detachment" or distress, this kind of distress is seen in individuals with prolonged grief disorder who show avoidant behaviors associated with detachment, such as, intense worrying and isolating behaviors (Maercker \& Lalor, 2012). The third factor, "intense negative behaviors" expresses an intense sensitivity related to loss stimuli, reminders of the loss as they are tossed helplessly onto waves of intense emotion, reveal specific feelings of: anger, bitterness, and envy (Shear, 2012). In regard to the fourth factor, labelled "loss impairing anxiety", it refers to numbness, daze and upsetting behaviors that follow up a prolonged grief (Shear, et al., 2011). Most people that experience normal bereavement and grief, present a period of sadness, sorrow, melancholia, and nostalgia in a temporary manner, and these feelings ease over time. In this case, most people gradually accept loss, allow themselves to experience reality, adjust their life without the loved one, and are capable of moving forward. For some individuals, feelings become persistent and debilitating and do not improve after time, this is commonly defined as complicated grief. 
There are however several limitations of this study. First of all, the age of participants included in the analyses ranged from 25 up to and just under the elderly age mark. Based on the latest theoretical developments, which affirm that adult maturity and the maturational changes that occur in the 21st century, considering the social conditions and demands of the environment (school, family and community), today's adolescents do not comply with the demands of adolescents in past decades in a relevant, continuous and cumulative way that prove that currently an adolescent does not test his cognitive, affective and motivational resources to adapt, independently, to an autonomous social life, until 23 or 25 years of age, which is when they present mostly characteristic behaviors of adults, interpersonal and social behaviors (Twenge \& Parke, 2017) typical of the transition to adult independence. Adulthood usually engages the period between approximately 25 and 60 years of age. Caution is however suggested when doing generalizations of findings here to participants younger than 25 years old.

It is relevant to explore the grief process in the younger population due to its impact on their mental health, such as elevated risk of insomnia, fatigue, and moderate to severe depression (Bylund-Grenklo, et al., 2016), that if persistent on adult age, it can affect the appropriate development. Future research could focus on validating measures of complicated grief in the younger population and the elderly.

Another limitation is that although the sample was large, it was mostly composed of women (88.2\% versus $11.7 \%$ males, respectively). Since the Covid Grief Platform offered free psychological treatment to all the population that had lost someone due to COVID-19 or another reason within the COVID-19 pandemic (masked), the treatment was open for everyone, not gender-based. However, this outcome confirms what has been previously observed, that in general men are more reluctant to search for psychological support 
compared to women (Liddon et al., 2018; Seidler et al.,2018). Therefore, efforts to present psychological interventions more appealing to more male participants are needed.

Providing an intervention completely free of charge to the general population while ensuring participant anonymity prevented us from gathering more data on socio demographics. In México, this format of self-applied interventions is not common and therefore persons may be more reluctant to answer if such information / Intervention is not readily available to them.

To the knowledge of the researchers, this is the first validation of the ICG in Mexico. Indeed, with the exception of a complicated grief scale validated in Colombia (GambaCollazos \& Navia, 2017), in Latin America this is still an understudied area. Mexican mental health professionals require a valid measure to evaluate the COVID-19 impact on grief.

Another strength of this study lies within the size of the sample compared to studies, validating other complicated grief scales. Although some relevant information was not possible to obtain (eg. higher rate of men, civil /relationship status), the data ensures a better representation of the Mexican Population living these situations, where according to the available literature, the measures developed or validated for or during the COVID19 pandemic are scarce.

Future studies should focus on the development of scales to evaluate the mental health status of the general population, not only for the COVID-19 pandemic, and to promote and integrate proper mental health interventions in low income and developing countries where progress in mental health services has been slow (Rathod, et al., 2017), where such conditions along with several other physical health complications (Ohrnberger, Fichera \& Sutton, 2017), may require budget from the public funding. 


\section{Conclusion}

Results indicate that the Inventory of Complicated Grief with Mexican population is valid, with good psychometric properties and an appropriate measure of complicated grief for Mexican adults. This measure could evaluate the impact of grief on patients, and therefore, aid to structure more appropriate and functional interventions for the general population in order to avoid or reduce the probability of developing more serious disorders, such as complicated grief disorder.

\section{Abbreviations}

Center for Epidemiologic Studies Depression Scale (CES-D)

Coronavirus disease (COVID-19)

Complicated Grief (CG)

Confirmatory Factor Analysis (CFA)

Exploratory Factor Analysis (EFA)

Inventory of Complicated Grief (ICG)

Kaiser-Meyer-Olkin (KMO)

World Health Organization (WHO)

\section{References}


Beck, A. T., Weissman, A., Lester, D., \& Trexler, L. (1974). The measurement of pessimism: The hopelessness scale. Journal of Consulting and Clinical Psychology, 42(6), 861-865. doi:10.1037/h0037562

Bertuccio, R. F., \& Runion, M. C. (2020). Considering grief in mental health outcomes of COVID-19. Psychological Trauma: Theory, Research, Practice, and Policy, 12(S1), S87S89.https://content.apa.org/doi/10.1037/tra0000723

Boelen, P. A., \& Smid, G. E. (2017). Disturbed grief: prolonged grief disorder and persistent complex bereavement disorder. BMJ (Clinical research ed.), 357, j2016. https://doi.org/10.1136/bmi.j2016

Boelen, P. A., van den Schoot, R., van den Hout, M. A., de Keijser, J., \& van den Bout, J. (2010). Prolonged grief disorder, depression and posttraumatic stress disorder are distinguishable syndromes. Journal of Affective Disorders, 125(1-3), 374-378. doi: 10.1016/j.jad.2010.01.076

Bylund-Grenklo, T., Fürst, C. J., Nyberg, T., Steineck, G., \& Kreicbergs, U. (2016). Unresolved grief and its consequences. A nationwide follow-up of teenage loss of a parent to cancer 6-9 years earlier. Supportive Care in Cancer, 24(7), 3095-3103. doi:10.1007/s00520-016-3118-1

Caycho-Rodríguez, T., Valencia, P. D., Vilca, L. W., Cervigni, M., Gallegos, M., Martino, P., ... Burgos Videla, C. (2021). Cross-cultural measurement invariance of the fear of COVID-19 scale in seven Latin American countries. Death Studies, 1-15. doi: $10.1080 / 07481187.2021 .1879318$ 
Carmassi, C., Shear, M.K., Massimetti, G., Wall, M., Mauro, C., Gemignani, S., Conversano, C., \& Dell'Osso, L. (2014). Validation of the Italian version Inventory of Complicated Grief (ICG): a study comparing CG patients versus bipolar disorder, PTSD and healthy controls. Comprehensive Psychiatry, 55(5),1322-1329. doi: 10.1016/j.comppsych.2014.03.001.

Costello, A.B., \& Osborne, J. (2005). Best practices in exploratory factor analysis: four recommendations for getting the most from your analysis. Practical Assessment, Research, and Evaluation, 10(7), 1-9. https://doi.org/10.7275/jyj1-4868

Dominguez-Rodriguez, A., Martínez-Luna, S. C., Hernández Jiménez, M.J., de la RosaGómez, A., Esquivel Santoveña, E.E., Arzola-Sánchez, C., Alvarez Silva, J., Solis Nicolas, A. M., Colmenero Guadián, A. M., Ramírez-Martínez, F. R. \& Castellanos Vargas, R. O. (2021). A Self-applied Multi-component Psychological Online Intervention Based on UX, for the Prevention of Complicated Grief Disorder in the Mexican Population During the COVID-19 Outbreak: Protocol of a Randomized Clinical Trial. Frontiers in Psychology, 12, 1-19. doi: 10.3389/fpsyg.2021.644782

Eisma, M. C., \& Tamminga, A. (2020). Grief Before and During the COVID-19 Pandemic: Multiple Group Comparisons. Journal of Pain and Symptom Management, 60(6), e1-e4. https://doi.org/10.1016/j.jpainsymman.2020.10.004

Eisma, M. C., Tamminga, A., Smid, G. E., \& Boelen, P. A. (2021). Acute grief after deaths due to COVID-19, natural causes and unnatural causes: An empirical comparison. Journal of Affective Disorders, 278, 54-56. https://doi.org/10.1016/j.jad.2020.09.049 
Gamba-Collazos, H. A., \& Navia, C. E. (2017). Adaptación del Inventario de Duelo Complicado en población colombiana (Adaptation of the Complicated Grief Inventory in the Colombian population). Revista colombiana de Psicología, 26(1), 15-30.

González-Forteza, C., Solís Torres, C., Jiménez Tapia, A., Hernández Fernández, I., González-González, A., Juárez García, F.,Medina-Mora, M.E. \& Fernández-Varela, H. M. (2011). Reliability and validity of CES-D depression scale in a census of students in high school and college level in Mexico City. [Confiabilidad y validez de la escala de depresión CES-D en un censo de estudiantes de nivel medio superior y superior, en la Ciudad de México] Salud Mental, 34(1), 53-59.

Grochot, M. (2018). Death and the Grieving Process: Transactional Analysis Contributions. International Journal of Transactional Analysis Research \& Practice, 9(2), 72-80 https://doi.org/10.29044/v9i2p72

Han, D. H., Lee, J. J., Moon, D. S., Cha, M. J., Kim, M. A., Min, S., Yang, J. H,.Lee, E. J.,Yoo, S. K., \& Chung, U. S. (2016). Korean version of inventory of complicated grief scale: psychometric properties in Korean adolescents. Journal of Korean medical science, 31(1), 114. doi10.3346/jkms.2016.31.1.114

Igarashi, N., Aoyama, M., Ito, M., Nakajima, S., Sakaguchi, Y., Morita, T., Shima, Y., \& Miyashita, M. Comparison of two measures for Complicated Grief: Brief Grief Questionnaire (BGQ) and Inventory of Complicated Grief (ICG). Japanese journal of clinical oncology, hyaa185. doi 10.1093/jjco/hyaa185

Johns Hopkins University (March 30, 2021). COVID-19 Dashboard by the Center of Systems Science and Engineering (CSSE) at Johns Hopkins University (JHU). 
https://www.arcgis.com/apps/opsdashboard/index.html\#/bda7594740fd40299423467b4

\section{$\underline{8 e 9 e c f 6}$}

Kokou-Kpolou, C. K., Fernández-Alcántara, M., \& Cénat, J. M. (2020). Prolonged grief related to COVID-19 deaths: Do we have to fear a steep rise in traumatic and disenfranchised griefs?. Psychological Trauma: Theory, Research, Practice, and Policy, 12(S1), S94. doi: 10.1037/tra0000798

Liddon, L., Kingerlee, R., \& Barry, J. A. (2018). Gender differences in preferences for psychological treatment, coping strategies, and triggers to help-seeking. British Journal of Clinical Psychology, 57(1), 42-58. doi:10.1111/bjc.12147

Lifshitz, R., Ifrah, K., Markovitz, N., Bluvstein, I., \& Shmotkin, D. (2020). Inventory of complicated grief: Factor structure among middle-aged and older bereaved parents. Death studies, 1-8. doi: $\underline{10.1080 / 07481187.2020 .1725931}$

Limonero, J., Lacasta, M., Maté, J. \& Prigerson, H. (2009). Adaptation to Spanish of the Inventory of Complicated Grief (Adaptación al castellano del inventario de duelo complicado). Medicina Paliativa. 16(5), 291-297.

López-Ortega, M., Torres-Castro, S. \& Rosas-Carrasco, O. (2016). Psychometric properties of the Satisfaction with Life Scale (SWLS): secondary analysis of the Mexican Health and Aging Study. Health and Quality of Life Outcomes. 14(1), 170. doi:10.1186/s12955-016-0573-9 
Ludwikowska-Świeboda, K., \& Lachowska, B. (2019). Polish version of the Inventory of Complicated Grief-preliminary validation. Psychiatria polska, 53(5), 1069-1086. doi: 10.12740/PP/91729

Maciejewski, P. K. (2009). Correction: Prolonged Grief Disorder: Psychometric Validation of Criteria Proposed for DSM-V and ICD-11. PLoS Med 10(12): 10.1371/annotation/a1d91e0d-981f-4674-926c-0fbd2463b5ea. https://doi.org/10.1371/annotation/a1d91e0d-981f-4674-926c-0fbd2463b5ea

Maercker, A., \& Lalor, J. (2012). Diagnostic and clinical considerations in prolonged grief disorder. Dialogues in clinical neuroscience, 14(2), 167-176. https://doi.org/10.31887/DCNS.2012.14.2/amaercker

Martínez, J. \& Caro, L. (2009). El análisis factorial confirmatorio y la validez de escalas en modelos causales. Anales de Psicología, 25(2), 368-374. https://www.researchgate.net/publication/49292132 El analisis factorial confirmatorio y la validez de escalas en modelos causales

Masferrer, L., Garre-Olmo, J. \& Caparrós, B. (2017). Factor structure and concurrent construct validity of the IDC among bereaved drug users (Estructura factorial y validez de constructo concurrente del IDC entre usuarios de drogas en duelo). Actas Españolas de Psiquiatría, 45(2), 47-55.

Morris, S.E., Moment, A., deLima, J. (2020). Caring for Bereaved Family Members During the COVID-19 Pandemic: Before and After the Death of a Patient. Journal of Pain and Symptom Management, 60 (2), 70-74. https://doi.org/10.1016/j.jpainsymman.2020.05.002. 
Ohrnberger, J., Fichera, E., \& Sutton, M. (2017). The relationship between physical and mental health: A mediation analysis. Social Science and Medicine, 195, 42-49. doi:10.1016/j.socscimed.2017.11.008

Osnaya, M. \& Pérez, J. (2012). Reliability and construct validity of the Beck Suicidal Ideation Scale in Mexican high school students. Alternativas en Psicología, 16, 16-25.

Payás, A. (2010). The tasks of grief: psychotherapy of mourning from an integrativerelational model.Barcelona: Paidós.

Prigerson, H. G., Maciejewski, P. K., Reynolds III, C. F., Bierhals, A. J., Newsom, J. T., Fasiczka, A., Frank, E., Doman, J., \& Miller, M. (1995). Inventory of Complicated Grief: a scale to measure maladaptive symptoms of loss. Psychiatry research, 59(1-2), 65-79. doi:10.1016/0165-1781(95)02757-2

Prigerson, H. G., Horowitz, M. J., Jacobs, S. C., Parkes, C. M., Aslan, M., Goodkin, K., Raphael, B., Marwit, S. J., Wortman, C., Neimeyer, R.,A., Bonanno, G., Block, S. D., Kissane, D., Boelen, P., Maercker, A., Litz, B.T., Johnson, J. G., First, M. B., \& Rathod, S., Pinninti, N., Irfan, M., Gorczynski, P., Rathod, P., Gega, L., \& Naeem, F. (2017). Mental health service provision in low- and middle-income countries. Health Services Insights, 10 doi:10.1177/1178632917694350

Seidler, Z. E., Rice, S. M., Ogrodniczuk, J. S., Oliffe, J. L., \& Dhillon, H. M. (2018). Engaging men in psychological treatment: A scoping review. American Journal of Men's Health, 12(6), 1882-1900. doi:10.1177/1557988318792157 
Shear, M. K., Simon, N., Wall, M., Zisook, S., Neimeyer, R., Duan, N., Reynolds, C., Lebowitz, B., Sung, S., Ghesquiere, A., Gorscak, B., Clayton, P., Ito, M., Nakajima, S., Konishi, T., Melhem, N., Meert, K., Schiff, M., O'Connor, M. D. ... Keshaviah, A. (2011). Complicated grief and related bereavement issues for DSM-5. Depression and Anxiety, 28(2), 103-117. https://doi.org/10.1002/da.20780

Shear, M. K. (2012). Grief and mourning gone awry: pathway and course of complicated grief. Dialogues Clinical Neuroscience. 14(2), 119-128. doi: $\underline{10.31887 / \mathrm{dcns} .2012 .14 .2 / \mathrm{mshear}}$

Shi, D., Lee, T., \& Maydeu-Olivares, A. (2018). Understanding the Model Size Effect on SEM Fit Indices. Educational and Psychological Measurement, 79(2), 1-25. https://doi.org/10.1177/0013164418783530

Sousa, V. D., \& Rojjanasrirat, W. (2011). Translation, adaptation and validation of instruments or scales for use in cross-cultural health care research: A clear and userfriendly guideline. Journal of Evaluation in Clinical Practice, 17(2), 268-274. doi:10.1111/j.1365-2753.2010.01434.x

Tabachnick, B. G. \& Fidell, L. S. (2007). Using multivariate statistics (5th edition). Pearson Education.

Thompson, B. (2004). Exploratory and Confirmatory Factor Analysis: understanding concepts and applications (1st ed.). American Psychological Association.

Twenge, J. M., \& Park, H. (2017). The Decline in Adult Activities Among U.S. Adolescents, 1976-2016. Child Development. doi:10.1111/cdev.12930 
Vázquez, C., Duque, A., \& Hervás, G. (2013). Satisfaction with life scale in a representative sample of spanish adults: Validation and normative data. The Spanish Journal of Psychology, 16, E82. doi:10.1017/sjp.2013.82

World Health Organization. (March 30, 2021). WHO Coronavirus (COVID-19) Dashboard. https://covid19. who.int

Figure 1.

Standardized Estimates Confirmatory Factor Analysis Diagram 


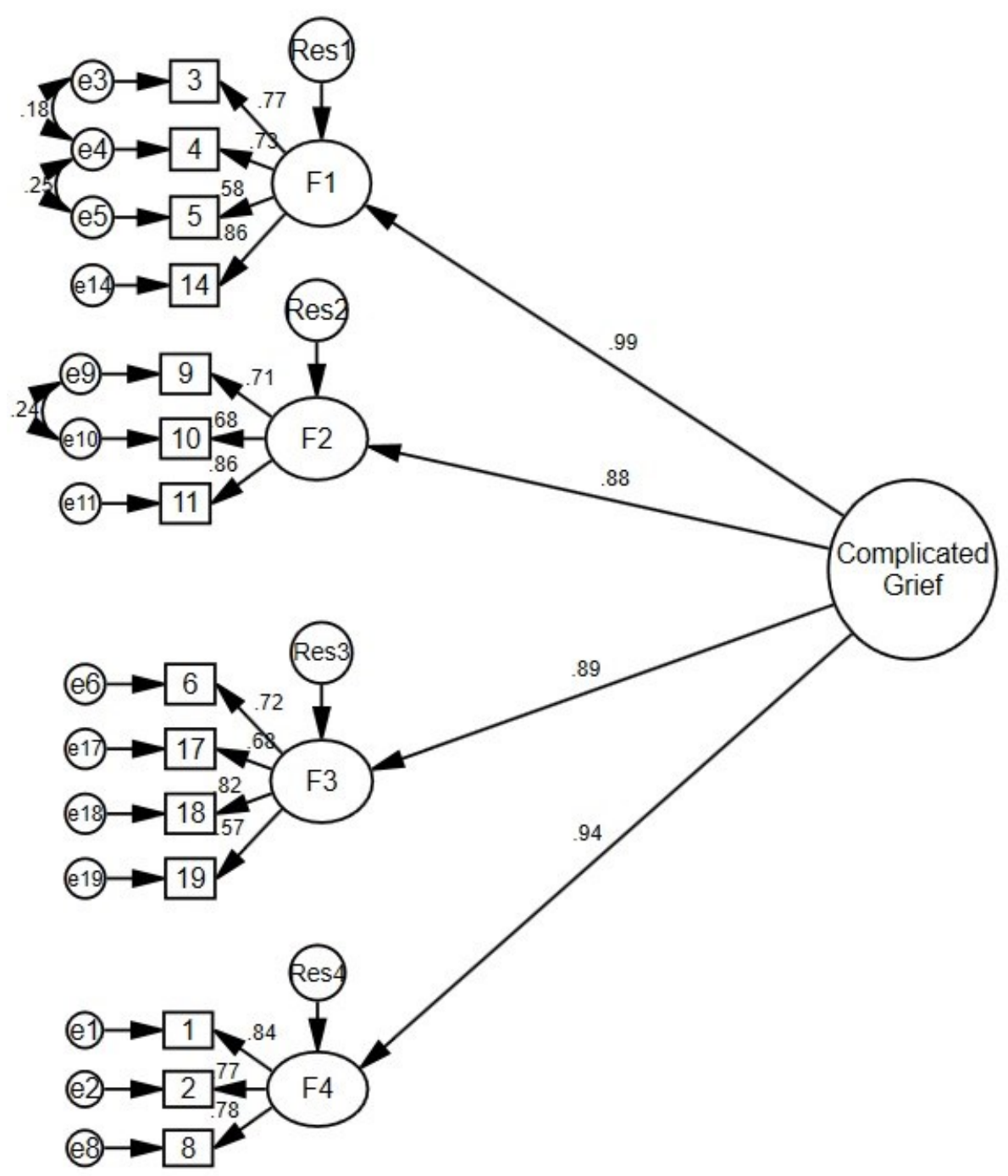

Table 1 


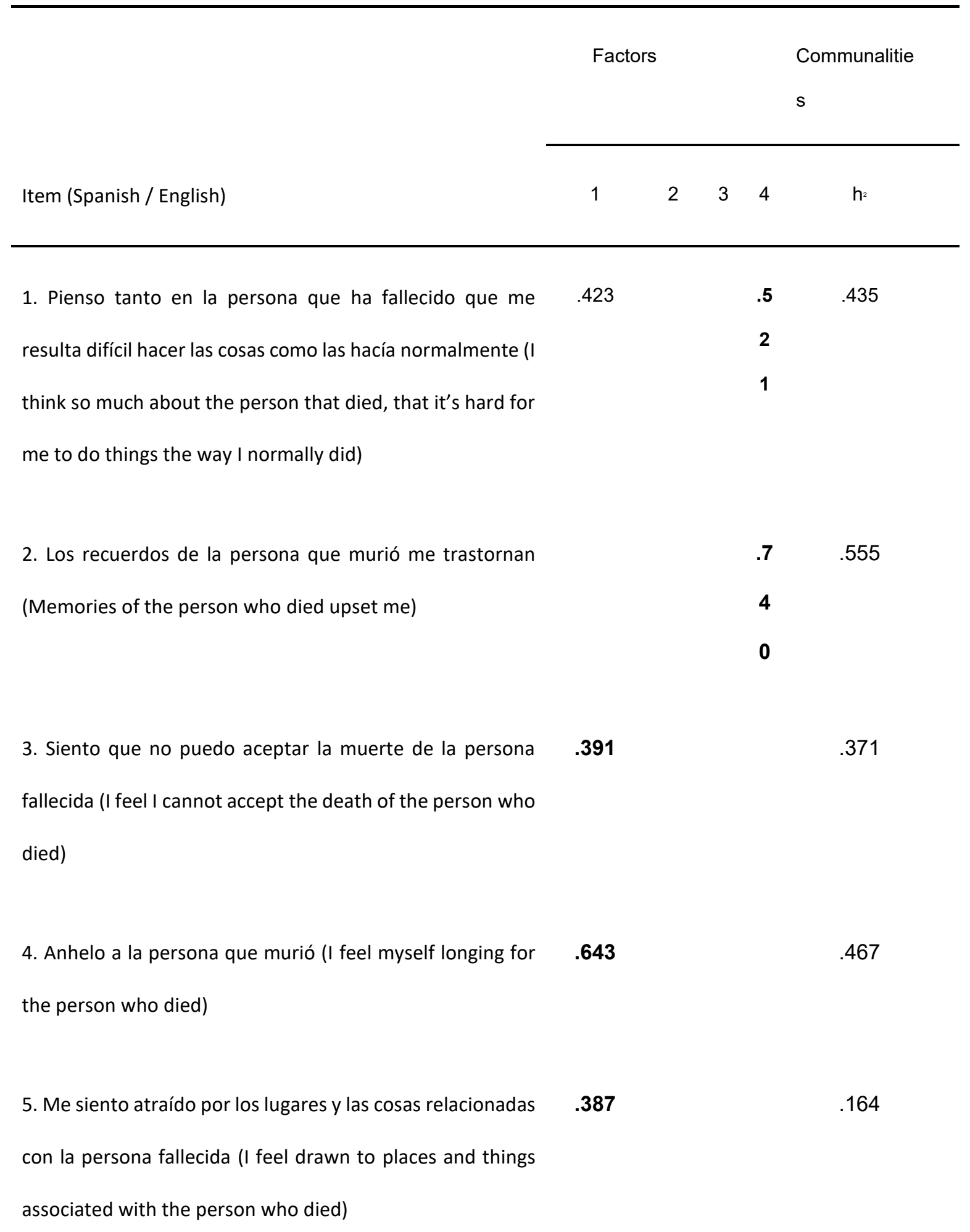


8. Me siento aturdido por lo sucedido (I feel stunned or dazed over what happened) people)

10. Siento haber perdido la capacidad de preocuparme de

preocupaban (Ever since he/she died, I feel as if I have lost the ability to care about other people or I feel distant from people I care about)

11. Me siento solo/a la mayor parte del tiempo desde que

since he/she died) feel that life is empty without the person who died) 
18. Siento amargura por la muerte de esa persona (I feel

.6

bitter over this person's death)

2

2

19. Siento envidia de otras personas que no han perdido a 
Table 2.

CFA Cronbach's alpha values for each of the four factors of the ICG

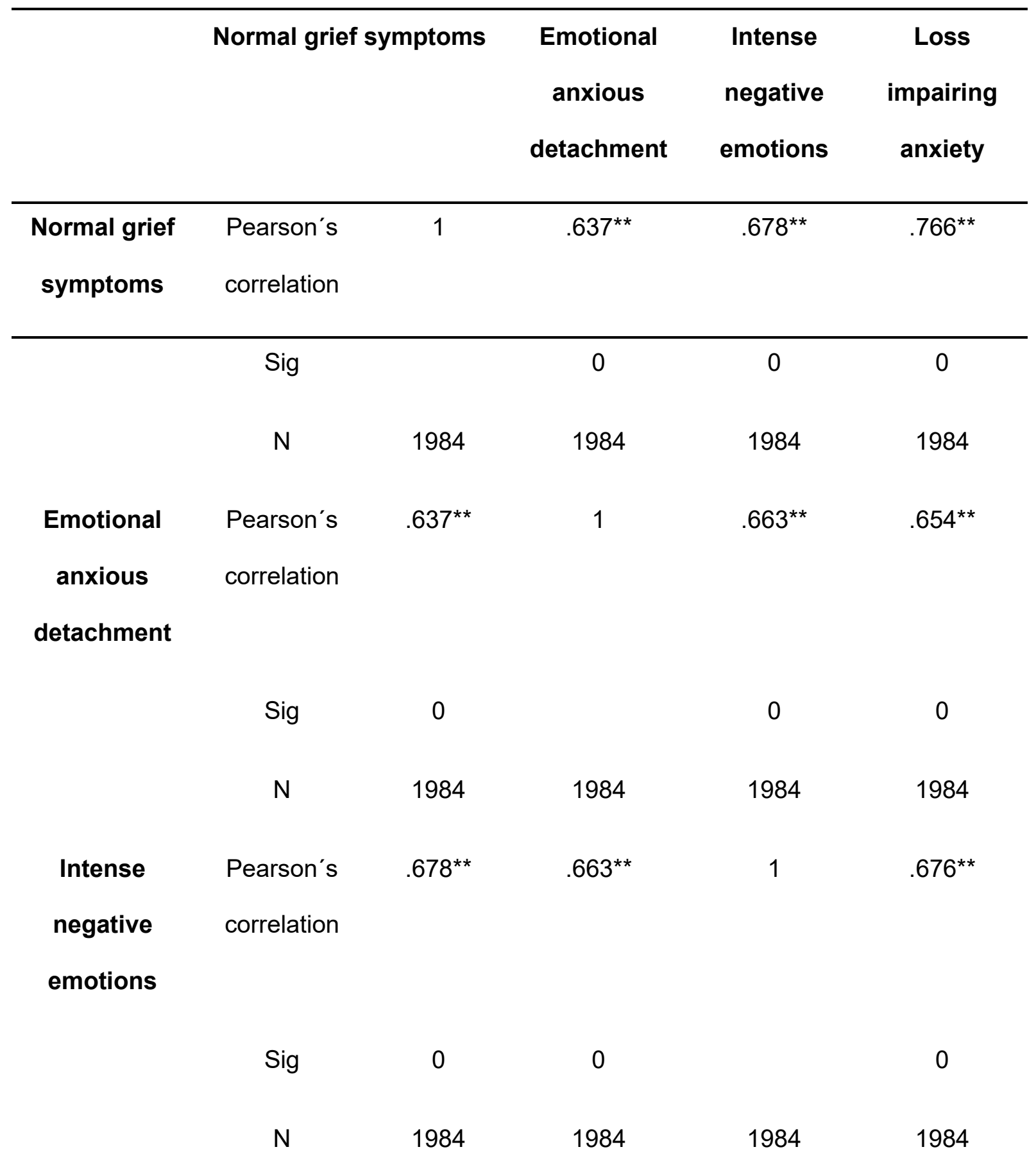




\begin{tabular}{cccccc} 
Loss & Pearson's & $.766^{* *}$ & $.654^{* *}$ & $.676^{* *}$ & 1 \\
impairing & correlation & & & & \\
anxiety & & & & & \\
& Sig & 0 & 0 & 0 & 1984 \\
& & 1984 & 1984 & 1984 & \\
\hline
\end{tabular}

